\title{
EFFECT OF ELECTRICAL STIMULATION ON BLOOD FLOW IN CALF MUSCLES IN DIFFERENT BODY POSITIONS
}

\author{
Julius Dovydaitis, Albinas Grūnovas \\ University of Applied Sciences Kauno Kolegija, Kaunas, Lithuania
}

\begin{abstract}
Background. In most studies on cardiovascular system, testing of subjects was performed in a horizontal position. With the change of the body position, certain functional changes occur in the cardiovascular system. The aim of this study was to analyze the effect of electrical muscle stimulation (EMS) on arterial and venous blood flows.

Methods. Eighteen athletes aged 19-23 performed two sessions of tests in horizontal and sitting positions. Changes in arterial and venous blood flows were recorded before and after EMS. In each session two occlusions were performed. In the horizontal position, the initial occlusion pressure of $20 \mathrm{mmHg}$ was applied and as the balance in arterial and venous blood flow rates was reached, the additional pressure of $20 \mathrm{mmHg}$ ( $40 \mathrm{mmHg}$ in total). In the sitting position, the occlusion pressure of 40 and $20 \mathrm{mmHg}$ was applied respectively ( $60 \mathrm{mmHg}$ in total). In both sessions EMS was performed using the electrical stimulator Mioritm 021.

Results. In both horizontal and vertical positions, the effect of EMS on arterial blood flow, venous reserve capacity and venous elasticity was insignificant. Arterial and venous blood flows was affected significantly by the change of the body position. In the sitting position, arterial blood flow was significantly $(p<.05)$ lower compared to the horizontal position. Similar results were recorded in venous reserve capacity.

Conclusion. The study suggests that blood flow in the calf muscles is affected by the body position and hydrostatic pressure; arterial blood flow increases in the horizontal body position.
\end{abstract}

Keywords: electrical muscle stimulation (EMS), arterial blood flow, venous reserve capacity, venous elasticity.

\section{INTRODUCTION}

$\mathrm{D}$ uring the training, different methods are used to improve functional capacities of muscles in athletes and one of these is electrical muscle stimulation (EMS). Muscles are affected by the intensity of stimulation and the duration of contraction and relaxation periods. The EMS exceeding threshold is often used to increase muscle strength and may vary even up to intolerable pain (Alon, Kantor, \& Smith, 1999; Gondin, Guette, Jubeau, Ballay, \& Martin, 2006)

The EMF method can be applied to develop muscle strength in healthy people (Bonerjee, Caulfield, Crowe, \& Clark, 2005; Maffiuleti et al., 2006; Malatesta, Cattaneo, Dugnani, \& Maffiuleti,
2003). The low intensity EMF increases maximal voluntary strength in sedentary and poorly performing people (Valli, Boldrini, Bianchedi, Brizzi, \& Miserocchi, 2002). The EMF procedures have a specific effect on the athlete's body and can be used for the enhancement of muscle recovery and for the increase of muscle power (Maffiuleti et al., 2006) to decrease muscle atrophy and to accelerate restoration of muscle functions after injuries (Faghri, Votto, \& Hovorka, 1998). Mild electrical stimulation of the calf muscle also known as electrical massage can be used to counteract venous stasis and to increase recovery of working muscles after the physical load (Kaplan, Czyrni, 
Fung, Unsworth, \& Hirsh, 2002). Skeletal muscle contraction evoked by the artificial EMS signals bears physiological resemblance to real skeletal muscle contraction (Gregory \& Bickel, 2005).

Blood flow in muscles during the physical load is an important factor influencing working capacity of muscles. Depending on the functional condition of skeletal muscles as well as environmental conditions, change in the intensity of skeletal muscle blood flow is observed even at rest (Wilmore, Costill, \& Larry, 2008). The effect of recovery modalities is associated with an increase in blood volume and its distribution from less active muscles to more active muscles (Laughlin, 1999).

The skeletal muscle electrical stimulation is an effective method for accelerating the recovery processes of muscle working capacity after intense exercise (Кибиша, Подерис, \& Грюновас, 1983). Any recovery method also has a certain effect as it requires an additional load on the body affecting its different systems (Платонов, 2004). EMS increases the velocity of venous blood flow in the calf muscles (Sochart \& Hardinge, 1999) and increases the venous blood pump of the calf muscles (Daley, 1960). However, available evidence about the effect of EMS on arterial and venous blood flow is insufficient.

Venous blood stasis in the legs can be provoked by the immobility due to injuries or after longhaul air travel (Kaplan et al., 2002). After surgery, EMS possibly causes more effective evacuation of venous blood from lower extremities.

The majority of studies on human cardiovascular system present results from the tests where subjects were placed in a horizontal position (lying on the back), but only a few studies were performed testing subjects in a vertical position. The sitting position is considered one of the vertical positions and humans spend two-thirds of their lifetime in the vertical position. A number of functional changes occur to the human cardiovascular system due to the change of the body position. The aim of this study was to analyze the effect of EMS on arterial and venous blood flow in different body positions.

\section{METHODS}

The study included two sessions of tests that were performed in the horizontal and sitting positions with 18 subjects aged 19-23 and adapted to physical loads. Venous blood flow signals were recorded with the venous occlusion plethysmography (VOP). The subjects lied in a horizontal position on their back with knees bent $\left(135^{\circ}\right)$ at rest after 20 minutes of adaptation. The calf which was a segment under examination was positioned on heart level.

Two successive occlusions were performed: the initial occlusion pressure of $20 \mathrm{mmHg}$ was applied and, as the balance in arterial and venous blood flow rates was reached, the additional occlusion pressure of $20 \mathrm{mmHg}$ was applied constituting the total occlusion pressure of $40 \mathrm{mmHg}$.

In the second session, blood flow signals were recorded in the same way as in the first session, only the occlusion pressure and the position of the calf differed. The initial occlusion pressure of $40 \mathrm{mmHg}$ was applied following by the additional occlusion pressure of $20 \mathrm{mmHg}$ that constituted together $60 \mathrm{mmHg}$. The recording of vascular tones using the VOP features certain characteristics. When the pressure in the cuff increases above venous pressure, the VOP starts to rise, which indicates the increase of volume in a segment under examination. Venous filling occurs during cuff occlusion and venous outflow decreases. The increase of venous pressure and blood volume in the extremity occurs up to the point when plethysmography displays a horizontal line. The increased blood volume is determined by the distension of venous blood vessel walls. The higher the distension of the blood vessels, the larger amount of blood can be collected in the veins. When the plethysmogram is in a horizontal position with the initial occlusion pressure of $20 \mathrm{mmHg}$, the cuff occlusion pressure is increased by $20 \mathrm{mmHg}$ and the total occlusion pressure constitutes $40 \mathrm{mmHg}$.

The study has been approved by Kaunas Regional Biomedical Research Ethics Committee. Both sessions of tests were performed using the electrical stimulator Mioritm 021. Previous studies on the effect of EMS on enduring physical loads showed that the optimal duration of the EMS application that helps to reach the highest working capacity is $10 \mathrm{~min}$ (Кибиша et al., 1983). The mode of an impulse was bipolar asymmetric with zero constant. The impulse formed a triangular shape. During continuous stimulation, the frequency of impulses was at $90 \mathrm{~Hz}$. Depending on individual characteristics of the subjects, the intensity of electrical stimulus was around $10-15 \mathrm{~mA}$. One electrode $(20 \times 3 \mathrm{~cm})$ was placed on the calf muscle proximal and another electrode $(14 \times 3 \mathrm{~cm})$ was placed on the distal area of the back. Finally, the data was analysed examining changes in arterial 
and venous blood flow in the horizontal and vertical positions.

The statistical analysis was performed using the statistical software SPSS Version 17.0. Student's $t$-test was used for the equality of the means in independent samples. Statistical significance of difference between two groups was determined using Student's $t$-test. The difference was considered statistically reliable if $p<.05$.

\section{RESULTS}

In the horizontal position, the arterial blood flow in subjects $(2.42 \pm 0.27 \mathrm{ml} / 100 \mathrm{ml} / \mathrm{min})$ at rest was significantly higher $(p<.05)$, compared to the vertical position $(1.74 \pm 0.12 \mathrm{ml} / 100 \mathrm{ml} / \mathrm{min})$. The change in the arterial blood flow in subjects in the horizontal position before and after EMS was insignificant compared to the initial value. Similar indications were observed in the arterial blood flow measured in the vertical (sitting) position before and after EMS (Figure 1). These results suggest that the intensity of arterial blood flow is affected by the body position.

In the horizontal position before EMS at the occlusion cuff pressure of $20 \mathrm{mmHg}$, the venous reserve volume in subjects was $3.12 \pm$ $0.6 \mathrm{ml} / 100 \mathrm{ml}$. After the additional occlusion pressure of $20 \mathrm{mmHg}$ was applied, at the occlusion cuff pressure of $40 \mathrm{mmHg}$, the venous reserve volume was $4.0 \pm 0.38 \mathrm{ml} / 100 \mathrm{ml}$. No significant change was observed in the venous reserve capacity in subjects before and after EMS (Figure 2).

In the vertical position before EMS at the occlusion cuff pressure of $40 \mathrm{~mm} \mathrm{Hg}$, the venous reserve volume was $1.7 \pm 0.11 \mathrm{ml} / 100 \mathrm{ml}$. After the additional occlusion pressure of $20 \mathrm{mmHg}$ was applied, at the occlusion cuff pressure of $60 \mathrm{mmHg}$, the venous reserve volume was $2.57 \pm 0.38 \mathrm{ml} / 100 \mathrm{ml}$. Just like in the horizontal position, the venous
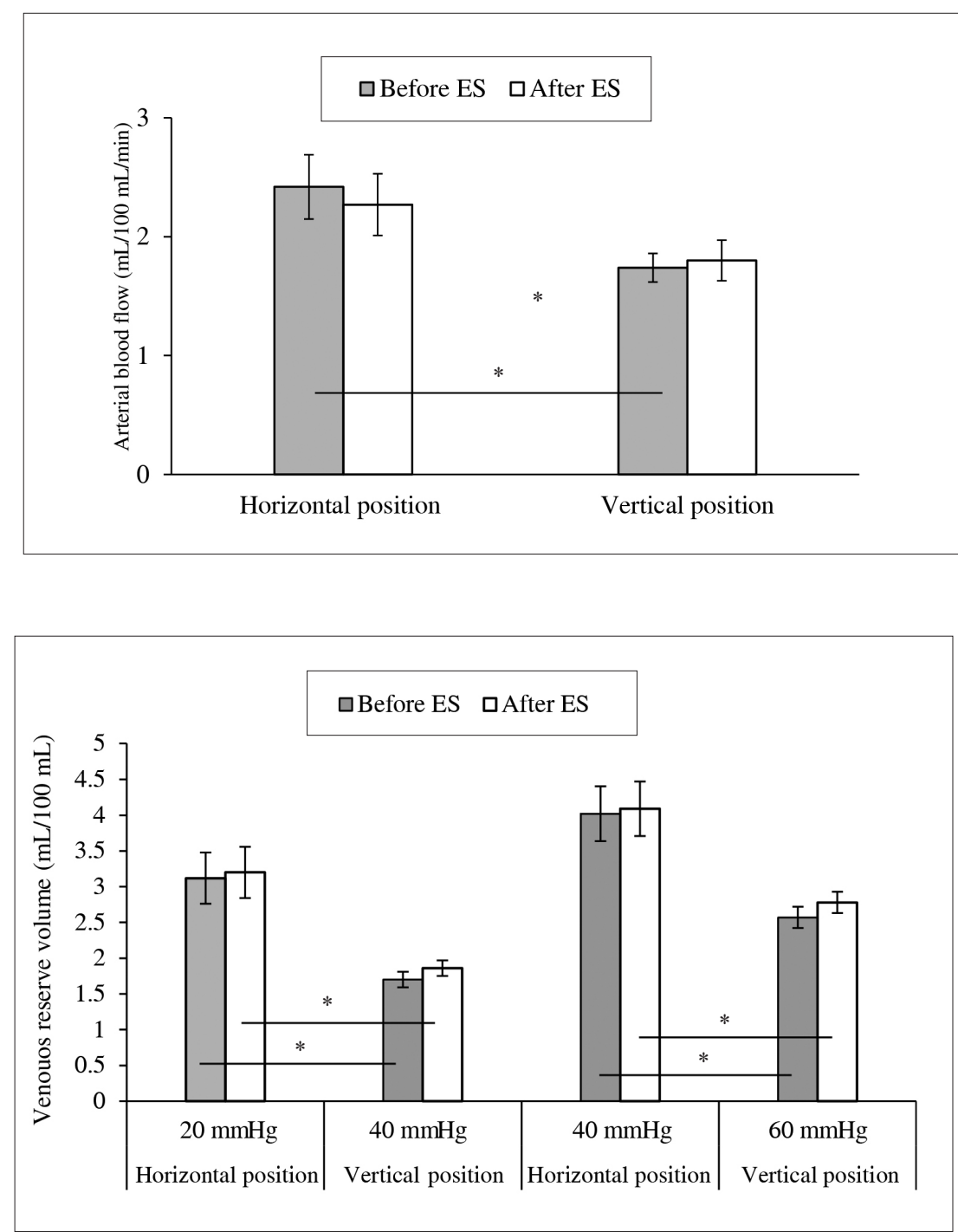

Figure 1. Change in arterial blood flow in the horizontal and vertical positions before and after the EMS $(\bar{x} \pm S \bar{x})$

Note. $*-p<.05$.

Figure 2. Change in venous reserve volume in the horizontal and vertical positions $(\bar{x} \pm S \bar{x})$

Note. $*-p<.05$. 
Figure 3. Change in venous elasticity $(\mathrm{ml} / 100 \mathrm{ml})$ in the horizontal and vertical positions $(\bar{x} \pm S \bar{x})$

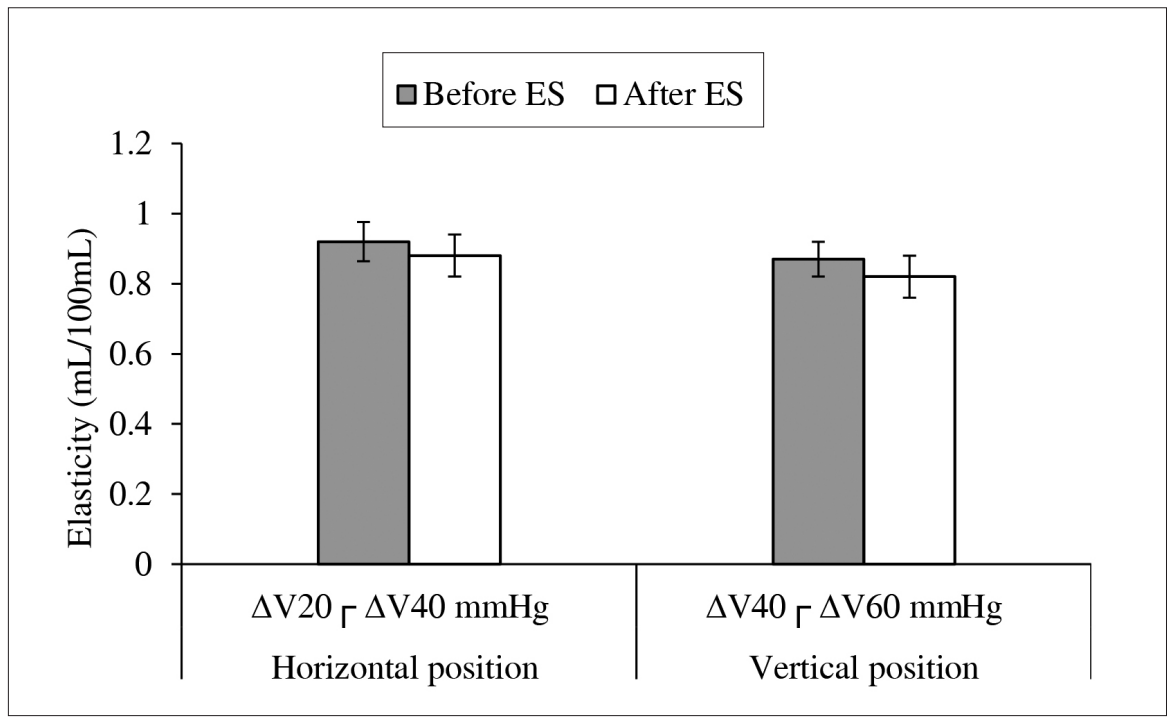

Figure 4. Duration of time to reach balanced arterial and venous blood flow rates in the horizontal position before, during and after the $\operatorname{EMS}(\bar{x} \pm S \bar{x})$

Note. ${ }^{*}-p<.05$

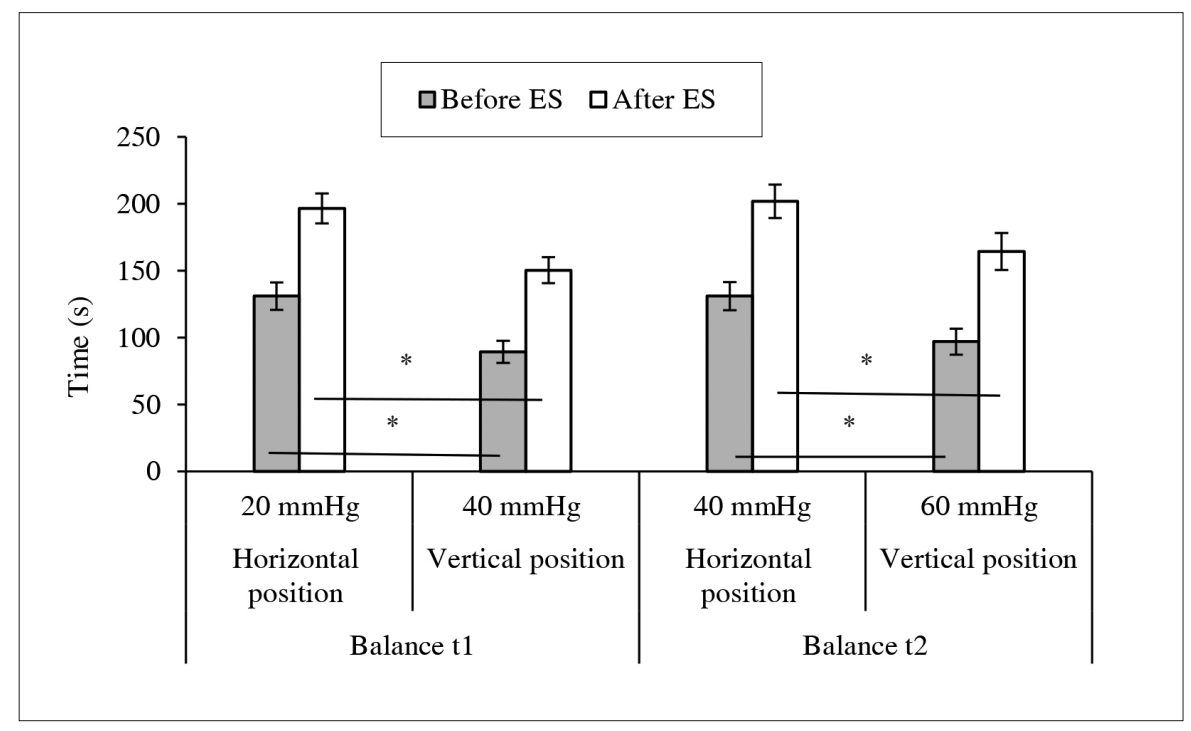

reserve capacity in subjects in the vertical position before and after EMS did not differ (Figure 2).

In the horizontal position, venous elasticity $\left(\Delta \mathrm{V}_{20} \Gamma \Delta \mathrm{V}_{40} \mathrm{mmHg}\right)$ in subjects was $0.92 \pm 0.06 \mathrm{ml} / 100 \mathrm{ml}$ before EMS and $0.88 \pm$ $0.06 \mathrm{ml} / 100 \mathrm{ml}$ after EMS.

In the vertical position, venous elasticity $\left(\Delta \mathrm{V}_{40} \Gamma\right.$ $\Delta \mathrm{V}_{60} \mathrm{mmHg}$ ) in subjects was $0.87 \pm 0.05 \mathrm{ml} / 100 \mathrm{ml}$ before EMS and $0.82 \pm 0.06 \mathrm{ml} / 100 \mathrm{ml}$ after EMS. No significant change was observed in venous elasticity in subjects between the horizontal and vertical positions (Figure 3).

In the horizontal position before EMS at the occlusion cuff pressure of $20 \mathrm{mmHg}$, the balance in arterial and venous blood flow rates was reached in $131.4 \pm 10.3 \mathrm{~s}$. After the additional occlusion pressure of $20 \mathrm{mmHg}$ was applied, at the occlusion cuff pressure of $40 \mathrm{mmHg}$, the balance in arterial and venous blood flow rates was reached in $196.6 \pm 11.3 \mathrm{~s}$.

In the vertical position before EMS at the occlusion cuff pressure of $40 \mathrm{mmHg}$, the balance in arterial and venous blood flow rates was reached in $89.4 \pm 8.2 \mathrm{~s}$. After the additional occlusion pressure of $20 \mathrm{mmHg}$ was applied, at the occlusion cuff pressure of $60 \mathrm{mmHg}$, the balance in arterial and venous blood flow rates was reached in $92.6 \pm$ $9.1 \mathrm{~s}$ (Figure 4). After EMS at the occlusion cuff pressure of $40 \mathrm{mmHg}$, balance in arterial and venous blood flow rates was reached during a longer period of time compared to the initial value than at the occlusion cuff pressure of $60 \mathrm{mmHg}$. No significant difference was observed in the duration of time required to reach balanced arterial and venous blood flow rates at different pressure levels $\left(\Delta \mathrm{V}_{40} \Gamma \Delta \mathrm{V}_{60} \mathrm{mmHg}\right)$ before and after EMS. 


\section{DISCUSSION}

When the body is in a horizontal position, the pressure of $6-9 \mathrm{mmHg}$ is needed to retain a oval shape in the venous blood vessel. Even under high pressure, the distension of the veins is low due to rigid collagen elements in the structure of the blood vessel wall (Wilmore et al., 2008). Under very low pressure, the veins become elliptical in shape. When the blood vessel circumference is equal, the lumen of the blood vessel elliptical in shape is lower than the lumen of the blood vessel oval in shape. When the venous pressure increases from 0 to $6 \mathrm{mmHg}$, venous volume in a segment changes significantly. The increase of venous circumference and elasticity show the change in venous reserve volume. Venous elasticity, i.e. an increase of the venous circumference, increases the flexibility of blood vessels evoking an insignificant force as it was noticed in the change of venous reserve volume. If the venous pressure is less than $6-9 \mathrm{mmHg}$, the veins collapse (Folkow \& Neil, 1971).

In both horizontal and vertical positions, EMS providing a mild massage had a small effect on the intensity of arterial blood flow. The strongest effect of EMS on venous reserve volume was when subjects were in a vertical position. The difference between values recorded in the study may be explained by the increased luminal diameter in the veins caused by the increase in hydrostatic pressure in the sitting position when venous blood vessels undergo transformation from elliptical to oval in shape. This change reduces the resistance of blood flow in venous blood vessels (Caro, Pedley, Schroter, \& Seed, 1978). In both horizontal and vertical positions, even though EMS caused extension and relaxation of the calf muscles, mild EMS had a small effect on venous blood volume in the calf. This assumption is also supported by the substantially longer duration needed for the plethysmography curve (balance in arterial and venous blood flows) to reach a new level of dynamic balance which indicates the degree of venous outflow. The increase in venous reserve volume observed in this study suggests that the decreased amount of blood in the veins results from the vertical body position. It is very probable that due to the decreased venous pressure, the resistance to the venous blood flow increases (Neubauer, 1977). Venous flow velocity is also affected by the position of the foot. When the foot is lower to the body in the horizontal position, e.g. the calf is lowered 25 degrees, venous flow velocity increases significantly because of the effect of the venous foot pump (Fleming, Fitzgerald, Devitt, Rice, \& Murray, 2000).

The results from this study may be applied in other studies when the optimum pressure should be selected for the occlusion of venous blood flow. Different conditions are created when the body is located in a different position (horizontal and vertical). In the horizontal body position, an optimum pressure for the partial occlusion of the veins would be $20 \mathrm{mmHg}$ and at the occlusion pressure higher than $20 \mathrm{mmHg}$ the restoration of balanced arterial and venous blood flow rates would be achieved in a long period of time. A similar situation would occur during the tests in the vertical body position. The occlusion pressure of $40 \mathrm{mmHg}$ is optimum to record the parameters of venous reserve volume. The increase of hydrostatic pressure and other factors affect the restoration of balanced arterial and venous blood flow rates.

\section{CONCLUSIONS}

1. When the body is in the horizontal or sitting position, EMS has no significant effect on arterial blood flow in persons adapted to physical loads. In the sitting position under the influence of hydrostatic pressure, arterial blood pressure is significantly lower compared to the horizontal position.

2. In the sitting position when hydrostatic pressure is absent, venous reserve capacity is significantly higher compared to the sitting position. Venous elasticity in the horizontal and vertical position respectively did not differ.

3. In the sitting position, the balance between arterial blood inflow and venous blood outflow was reached significantly faster compared to the horizontal position. 


\section{REFERENCES}

Alon, G., Kantor, G., \& Smith, G. V. (1999). Peripheral nerve excitation and plantar flexion force elicited by electrical stimulation in males and females. The Journal of Orthopaedic and Sports Physical Therapy, 29(4), 208-214.

Bonerjee, P., Caulfield, B., Crowe, L., \& Clark, A. (2005). Prolonged electrical muscle stimulation exercise improves strength and aerobic capacity in healthy sedentary adults. Journal of Applied Physiology, 99(6), 2307-2311.

Caro, C. G., Pedley, T. J., Schroter, R. C., \& Seed, W. A. (1978). The mechanics of the circulation. Oxford: Oxford University Press.

Daley, R. (1960). Pulmonary embolism. Disorders of pulmonary circulations. London.

Faghri, P. D., Votto, J. J., \& Hovorka, C. F. (1998). Venous hemodynamics of the lower extremities in response to electrical stimulation. Archives of Physical Medicine and Rehabilitation, 79(7), 842-848.

Fleming, P., Fitzgerald, P., Devitt, A., Rice, J., \& Murray, P. (2000). The effect of the position of the limb on venous impulse foot pumps. The Journal of Bone and Joint Surgery (Br), 82(3), 433-434.

Folkow, B., \& Neil, E. (1971). Circulation. New York: Oxford University Press.

Gondin, J., Guette, M., Jubeau, M., Ballay, Y., \& Martin, A. (2006). Central and peripheral contributions to fatigue after electrostimulation training. Medicine and Science in Sports and Exercise, 38(6), 1147-1156.

Gregory, C. M., \& Bickel, C. S. (2005). Recruitment patterns in human skeletal muscle during electrical stimulation. Physical Therapy, 85(4), 358-364.

Kaplan, R. E, Czyrni, J. J, Fung, T. S, Unsworth, J. D., \& Hirsh, J. (2002). Electrical foot stimulation and implications for the prevention of venous thromboembolic disease. Thrombosis and Haemostasis, 88(2), 200-204.
Laughlin, M., H. (1999). Cardiovascular response to exercise. Advances in Physiology Education, 22(1), 244-259.

Maffiuleti, N. A., Zory, M., Miotti, D., Pellegrino, M. A., Jubeau, M., \& Bottinelli, R. (2006). Neuromuscular adaptations to electrostimulation resistance training. American Journal of Physical Medicine and Rehabilitation, 85(2), 167-175.

Malatesta, D., Cattaneo, F., Dugnani, S., \& Maffiuleti, N. A. (2003). Effects of electrostimulation training and volleyball practice on jumping ability. Journal of Strength and Conditioning Research, 17(3), 573-579.

Neubauer, B. (1977). Tilted and non-tilted postishaemic exercise peak flow in the legs of normal human subjects. Scandinavian Journal of Clinical and Laboratory Investigation, 37(1), 59-62.

Sochart, D. H, \& Hardinge, K. (1999). The relationship of foot and ankle movements to venous return in the lower limb. The Journal of Bone and Joint Surgery (Br), 81(4), 700-704.

Valli, P., Boldrini, L., Bianchedi, D., Brizzi, G., \& Miserocchi, G. (2002). Effect of low intensity electrical stimulation on quadriceps muscle voluntary maximal strength. The Journal of Sports Medicine and Physical Fitness, 42(4), 425-430.

Wilmore, J. H., Costill, D. L., \& Larry, K. W. (2008). Physiology of sport and exercise. Human Kinetics

Кибиша, Р. П., Подерис, И. А., \& Грюновас, А. П. (1983). Применение электростимуляции мыши и пассивных движений стоп для восстановления работоспособности. (Electrical stimulation and passive foot movement used for recovery working capacity). Методические рекомендации. Каунас.

Платонов, В. Н. (2004). Система подготовки спортсменов в олимпийском спорте. Общзая теория и ее практическое приложение. Киев: Олимпийская литература.
Corresponding author Julius Dovydaitis University of Applied Sciences Kauno Kolegija Petrausko str.15, LT-44221 Kaunas

Lithuania

Tel. +370 37330149

E-mail julius.dovydaitis@go.kauko.lt 